\title{
Novel uses of immunohistochemistry in breast pathology: interpretation and pitfalls
}

\author{
Ashley Cimino-Mathews ${ }^{1}$
}

Received: 1 July 2020 / Revised: 24 September 2020 / Accepted: 24 September 2020 / Published online: 27 October 2020

(c) The Author(s), under exclusive licence to United States \& Canadian Academy of Pathology 2020

\begin{abstract}
Immunohistochemistry is an essential component of diagnostic breast pathology. The emergence of novel assays and applications is accompanied by new interpretation criteria and potential pitfalls. Immunohistochemistry assists in supporting breast origin for primary or metastatic carcinomas and identifying non-mammary metastases to the breast; however, no single immunostain is perfectly sensitive nor specific. GATA3 and Sox10 are particularly useful immunostains to identify triple negative breast carcinoma, which are often negative for other markers of mammary differentiation. Sox 10 labeling is a major potential diagnostic pitfall, as Sox10 and S-100 label both triple negative breast carcinoma and metastatic melanoma; a pan-cytokeratin immunostain should always be included for this differential diagnosis. Novel immunohistochemistry serves as surrogates for the molecular alterations unique to several of special-type breast carcinomas, including the use of MYB in adenoid cystic carcinoma, pan-TRK in secretory carcinoma, and mutant IDH2 in tall cell carcinoma with reversed polarity (TCCRP). In addition, PD-L1 immunohistochemistry is an emerging, albeit imperfect, biomarker for breast cancer immunotherapy, with different assay parameters and scoring criteria in breast carcinoma compared to other tumor types. The expanding repertoire of novel immunohistochemistry provides additional diagnostic tools and biomarkers that improve diagnostic breast pathology and patient care.
\end{abstract}

\section{Introduction}

Immunohistochemistry has numerous important applications in diagnostic breast pathology, from helping to differentiate between benign epithelial hyperplasias and neoplastic proliferations to serving as predictive and prognostic biomarkers that aid in guiding patient treatment. This review covers a subset of novel uses, interpretation, and pitfalls of immunohistochemistry in breast pathology. Specifically, this review focuses on the use of immunohistochemistry in the following scenarios: (1) supporting breast origin of a carcinoma, (2) classifying metastases to the breast, (3) identifying specific molecular changes in special-type breast carcinomas, and (4) evaluating PD-L1 status as an emerging biomarker in

\footnotetext{
Ashley Cimino-Mathews
}

acimino1@jhmi.edu

1 Department of Pathology and Oncology, The Johns Hopkins University School of Medicine, 401N Broadway St Weinberg Bldg 2242, Baltimore, MD 21231, USA triple negative (estrogen receptor $[\mathrm{ER}]^{-} /$progesterone receptor $[\mathrm{PR}]^{-} /$human epidermal growth factor receptor-2 [HER-2 $^{-}$) breast carcinoma.

\section{Immunohistochemistry to support breast origin}

The list of immunohistochemistry that can support breast origin in a carcinoma continues to grow, but so too does the list of caveats in their interpretation. No single immunostain is entirely specific for breast carcinoma, and the estrogen receptor (ER) status of the carcinoma impacts the immunostain sensitivity. Supporting mammary origin of an $\mathrm{ER}^{+}$breast carcinoma is relatively straightforward (although not without potential pitfalls), because these carcinomas label for many of the "mammary marker" immunostains, including gross cystic disease fluid protein (GCDFP) and mammaglobin. In contrast, supporting mammary origin of an $\mathrm{ER}^{-}$or triple negative breast carcinoma can be more challenging; however, the use of GATA 3 and Sox 10 can be useful in this setting. Finally, both $\mathrm{ER}^{+}$and $\mathrm{ER}^{-}$breast carcinomas can label for S-100, which presents a significant potential diagnostic pitfall with melanoma. 


\section{GCDFP and mammaglobin}

Mammaglobin and GCDFP are commonly used as immunohistochemistry markers of mammary origin. Mammaglobin is more sensitive than GCDFP, but both label the majority of $\mathrm{ER}^{+}$breast carcinomas as well as HER-2 ${ }^{+}$ breast carcinomas [1-4] (Fig. 1). However, mammaglobin and GCDFP have markedly lower sensitivity for triple negative breast carcinoma ( $<35 \%$ and $16 \%$, respectively) $[2,4,5]$, and have limited diagnostic utility in this context. Both immunostains are cytoplasmic and often show variable or focal labeling across a carcinoma, which necessitates careful examination of the entire slide. GCDFP is more specific for breast carcinoma than mammaglobin $[1,3]$. The main differential diagnosis to consider in a carcinoma that labels for GCDFP and mammaglobin is adnexal carcinoma such as apocrine carcinoma; however, this distinction can usually be resolved by identifying an associated carcinoma in situ or by reviewing the clinical presentation of whether the mass is centered in the breast or dermis.

\section{GATA3}

GATA3 is a transcription factor involved in the differentiation of many tissue types, including the breast luminal epithelial cells [6], and GATA3 is linked to ER signaling in breast cancer [5]. GATA3 is a superior marker for $\mathrm{ER}^{+}$ breast carcinoma than GCDFP or mammaglobin, with labeling consistently reported in over $90 \%$ of $\mathrm{ER}^{+}$breast carcinomas $[3-5,7]$. In addition, GATA3 is more sensitive for triple negative breast carcinomas, with labeling commonly reported in over $50-83 \%[4,5,7,8]$, and has greater utility than GCDFP or mammaglobin in this context. GATA3 also displays nuclear rather than cytoplasmic labeling (Fig. 2), which can be easier to interpret, and shows strong and diffuse labeling in nearly all $\mathrm{ER}^{+}$breast carcinomas. GATA3 also labels lymphocytes, which serve as useful internal controls in GATA3 $^{-}$tumors (Fig. 3). GATA3 is not specific for breast carcinoma, however, and also labels urothelial carcinomas, squamous cell carcinomas, and mesotheliomas, with labeling in smaller numbers of pancreatic adenocarcinomas, lung adenocarcinomas, and others [5, 7], as discussed below.

\section{Sox 10}

The transcription factor Sox10 is involved in the differentiation of neural crest cells [9], and Sox10 immunohistochemistry was originally described as a marker of neural crest derivation, with labeling in melanomas and peripheral nerve sheath tumors [10,11]. Sox 10 also labels myoepithelial cells of the breast and salivary glands [11], with corresponding labeling in a subset of breast and salivary gland neoplasms with myoepithelial or basal celllike differentiation [10-12]. Sox 10 rarely labels $\mathrm{ER}^{+}$ carcinomas, but labels $66-74 \%$ of triple negative breast carcinomas [12, 13], and can be useful even when GATA3 labeling is negative [14, 15] (Fig. 3). Sox10 also displays nuclear labeling, and peripheral nerve Schwann cells can serve as a positive internal control. The main diagnostic pitfall, as further described below, is metastatic melanoma $[10,11]$.
Fig. 1 GCDFP in $\mathbf{E R}^{+}$breast carcinoma. Nearly all $\mathrm{ER}^{+}$ breast carcinomas, especially those with low- to intermediategrade histology (A, B) and strong, diffuse ER labeling $(\mathbf{C})$, will label for GCDFP (cytoplasmic) (D), mammaglobin (not shown), and GATA3 (not shown).

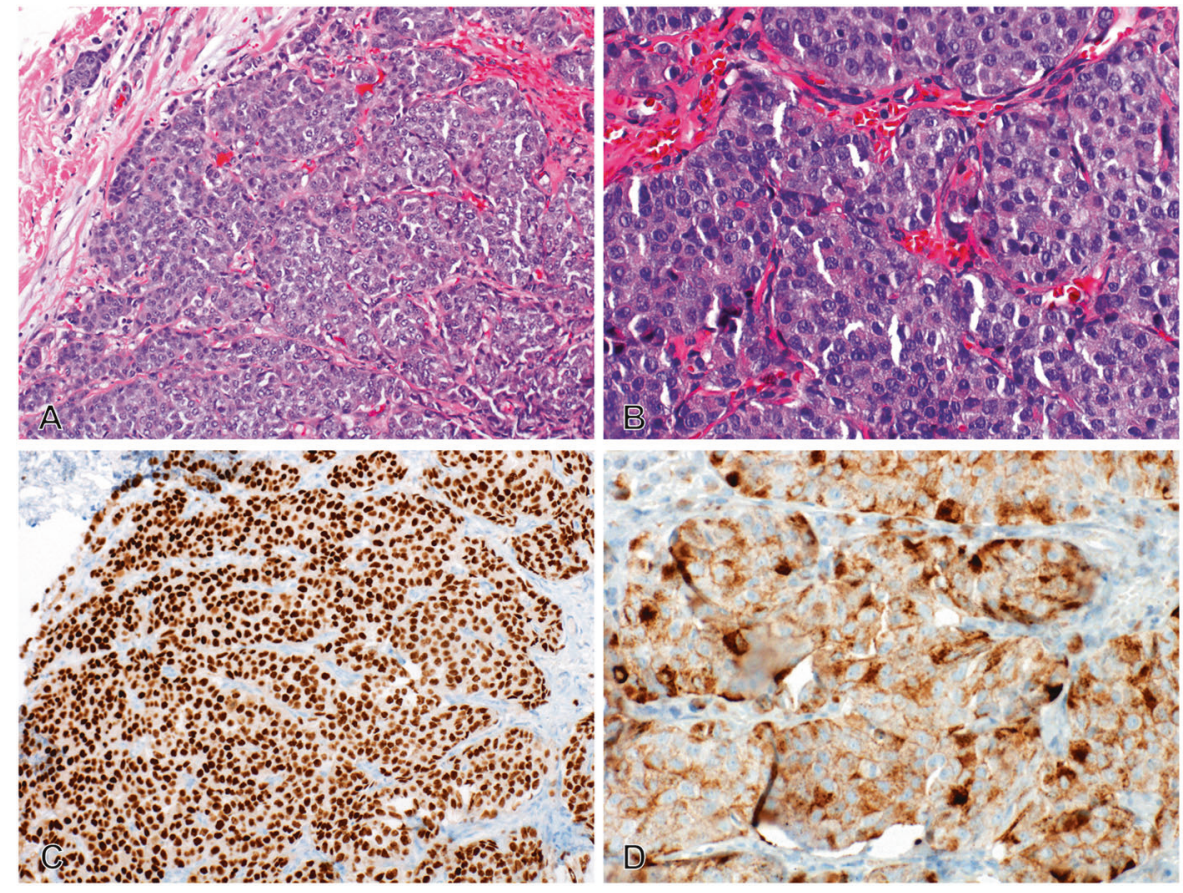


Fig. 2 GATA3 in triple negative breast carcinoma. Triple negative breast carcinomas often display highgrade cytology (A) and may require immunohistochemistry for pan-cytokeratin (AE1/AE3) to confirm classification as carcinoma (B). Despite showing no $(<1 \%)$ labeling for ER $(\mathbf{C})$, triple negative breast carcinomas may show diffuse nuclear GATA3 labeling (D).
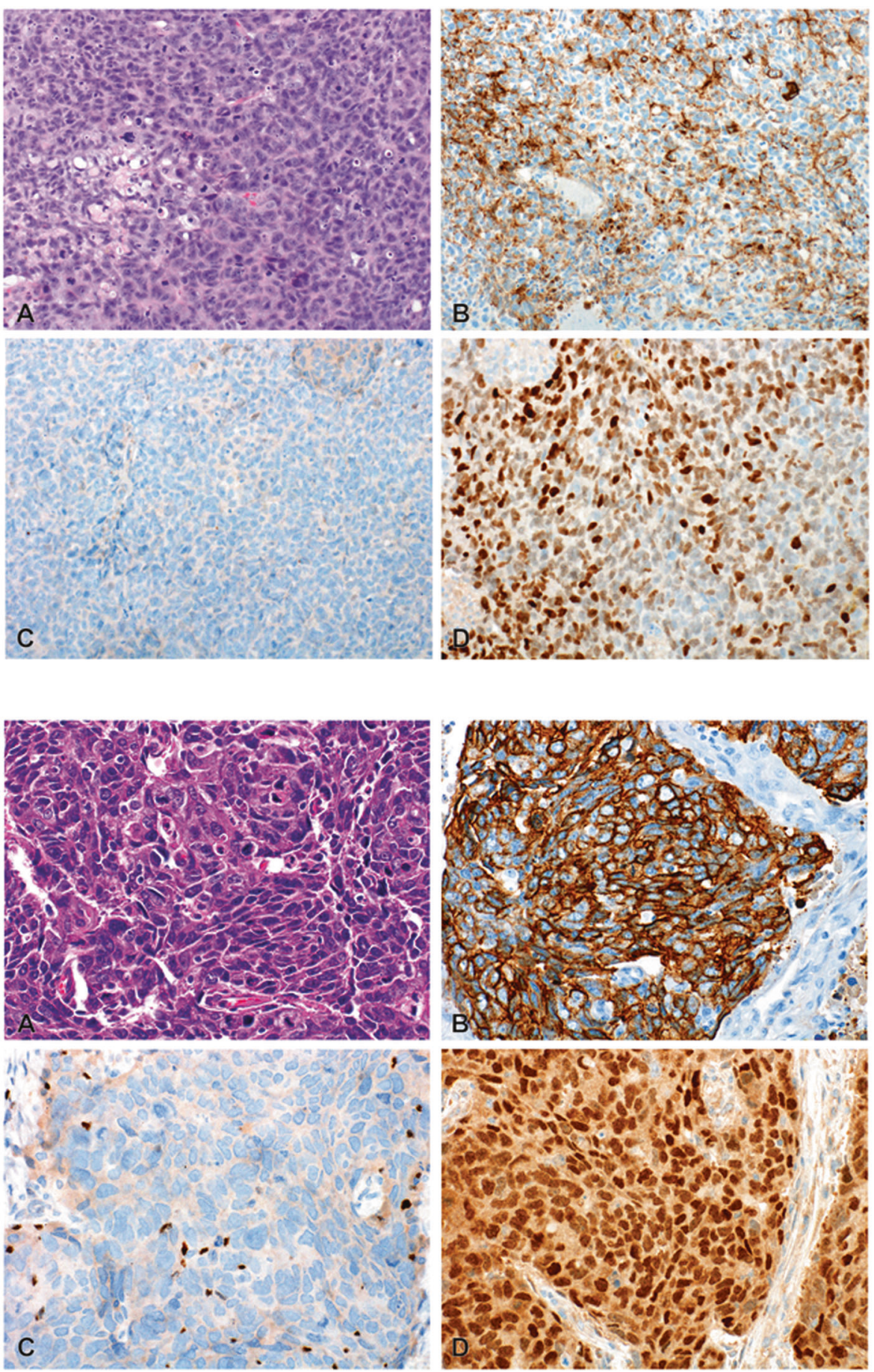

Fig. 3 Sox10 in triple negative breast carcinoma. High-grade triple negative breast carcinoma (A) is confirmed to be epithelial by labeling with pan-cytokeratin (Cam5.2) (B). The carcinoma may be negative for nuclear GATA3, with intact lymphocyte labeling as an internal control (C), but display strong and diffuse nuclear Sox10 labeling (D).

\section{S-100}

Like Sox 10, immunohistochemistry for S-100 is a marker of neural crest derivation in tumors and also labels myoepithelial cells of the breast and salivary gland. Although not typically thought of as a "breast marker," immunohistochemistry for S-100 does in fact label both $\mathrm{ER}^{+}$and ER breast carcinomas [16] (Fig. 4). As with Sox10, the main diagnostic pitfall with $\mathrm{S}-100$ is with metastatic melanoma.

\section{Immunohistochemistry in metastases to the breast or cancer of unknown origin}

Although a breast tumor is by far more likely to be a primary breast carcinoma than a metastasis to the breast, it is crucial that metastases to the breast are identified for correct patient management. Metastases to the breast occur in both females and males, are seen across age groups, and include lymphomas, melanoma, 
Fig. $4 \mathrm{~S}-100$ in breast carcinoma. A high-grade ER neoplasm with granular cytoplasm (A) may require labeling with pan-cytokeratin (AE1/AE3) to confirm epithelial differentiation (B) and labeling with nuclear GATA3 to support breast origin $(\mathbf{C})$. The presence of positive nuclear and cytoplasmic S-100 labeling (D) might otherwise suggest melanoma or granular cell tumor.

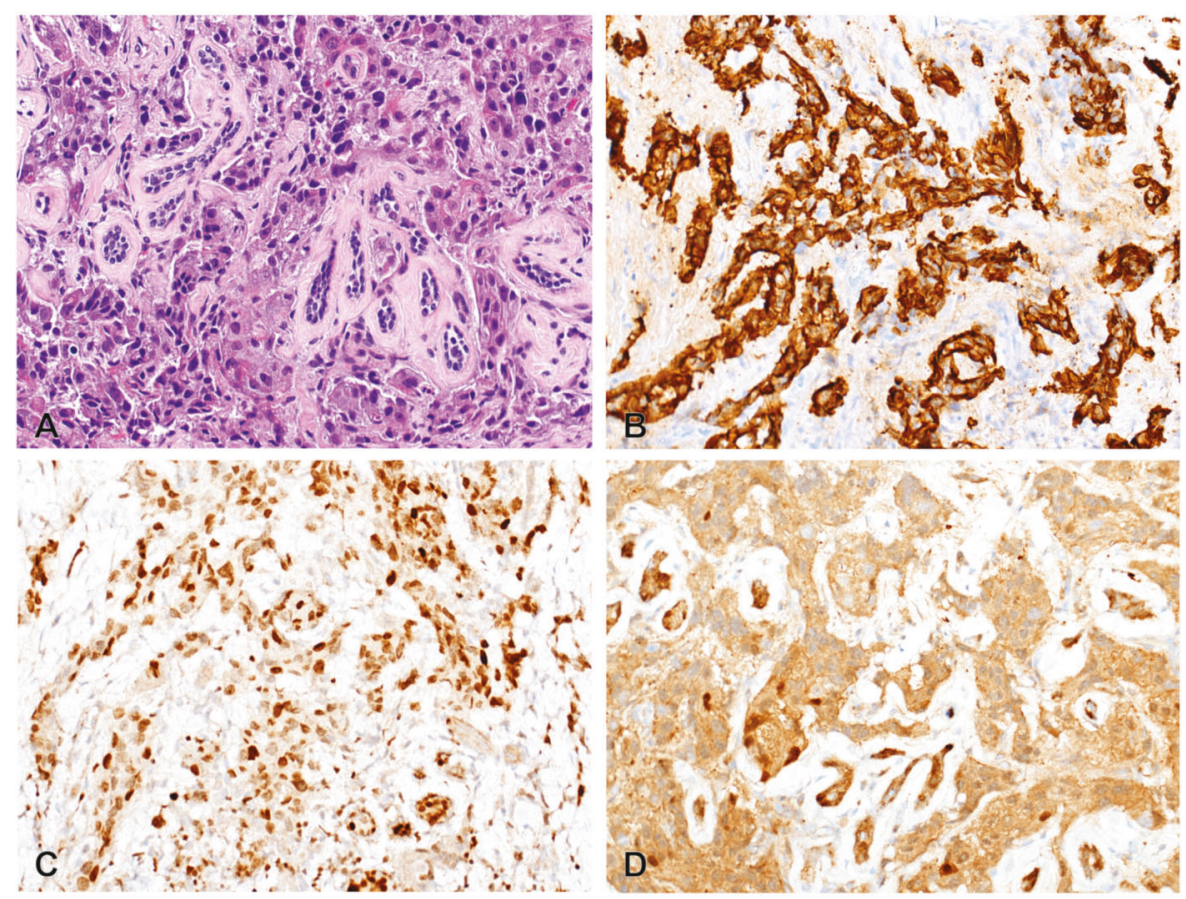

Table 1 Targeted immunopanels and pitfalls when determining cancer site of origin.

\begin{tabular}{|c|c|c|c|}
\hline Primary tumor & Pertinent positive immunohistochemistry & Pertinent negative immunohistochemistry & Potential pitfalls \\
\hline $\mathrm{ER}^{+}$breast cancer & ER, GCDFP, MMGB, GATA3, CK7 & CK20, TTF-1, CDX2 & \\
\hline $\mathrm{ER}^{-}$breast cancer & GATA3, Sox10, cytokeratin & ER, GCDFP, MMGB & Melanoma is $\mathrm{S}-100^{+} / \mathrm{Sox} 10^{+}$ \\
\hline Melanoma & S-100, Sox10, HMB45, Melan A, MITF & Cytokeratin & $\mathrm{TNBC}$ can be $\mathrm{S}-100^{+} / \mathrm{Sox} 10^{+}$ \\
\hline Lung adenocarcinoma & TTF-1, Napsin A & & Can be $\mathrm{GATA}^{+} / \mathrm{ER}^{+}$ \\
\hline High-grade serous & ER, WT-1, PAX8 & GATA3, GCDFP & Breast cancer can be WT- $1^{+}$ \\
\hline Prostate cancer & PSA, P501S, NKX3.1 & ER, GATA3 & $\begin{array}{l}\text { ILC and male IDC can be } \\
\text { NXK } 3.1^{+}\end{array}$ \\
\hline GI adenocarcinoma & $\mathrm{CDX} 2, \mathrm{CK} 20$, or $\mathrm{CK} 7$ & DPC4 (subset) & Can be GATA $^{+}$ \\
\hline
\end{tabular}

$E R$ estrogen receptor, GCDFP gross cystic disease fluid protein, GI gastrointestinal, $I D C$ invasive ductal carcinoma, $I L C$ invasive lobular carcinoma, $M M G B$ mammaglobin, $T N B C$ triple negative breast carcinoma.

carcinomas, and sarcomas $[17,18]$. In both female and male adults, the most-common non-hematopoietic metastasis to the breast is melanoma, followed by lung carcinoma. These tumors, along with metastatic highgrade serous carcinoma, prostatic adenocarcinoma, and gastrointestinal tract and pancreatic adenocarcinomas, each have immunohistochemical overlap with primary breast carcinoma and present significant potential diagnostic pitfall. The use of a targeted immunopanel is critical, if not essential, to identifying and classifying a metastasis to the breast. A targeted immunopanel should include a limited number of immunostains that are predicted to be positive and negative in each entity in the differential diagnosis [3, 19, 20]. A summary of key immunostains and potential pitfalls is provided in Table 1.
It is not always necessary to use immunohistochemistry to confirm primary breast origin of a tumor in the breast. Tumor morphology, the presence of carcinoma in situ, and clinical presentation can be sufficient. However, metastasis to the breast should be considered in the clinical setting of a known non-breast cancer history or widespread metastatic disease of unknown origin [17]. The need for a thorough clinical history cannot be emphasized enough. Pathologists should also consider a metastasis to the breast in the setting of unusual morphology in a breast tumor [21], as summarized in Table 2.

\section{Melanoma}

Melanoma has both morphologic and immunophenotypic overlap with high-grade carcinoma, particularly triple 
Table 2 Clinical and histologic features that prompt consideration of a metastasis to the breast.

Clinical presentation

Widespread metastatic disease of

unknown origin

Known non-breast cancer history

Unusual morphology

\begin{tabular}{|c|c|}
\hline Histologic feature & Differential to consider \\
\hline Melanin pigment & Melanoma \\
\hline Discohesion and high N/C ratio & Lymphoma \\
\hline Well-differentiated glands that are $\mathrm{ER}^{+}$ & $\begin{array}{l}\text { Lung or GI tract } \\
\text { adenocarcinoma }\end{array}$ \\
\hline Micropapillary carcinoma in the axilla & $\begin{array}{l}\text { High-grade serous } \\
\text { carcinoma }\end{array}$ \\
\hline $\begin{array}{l}\text { High-grade malignant neoplasm with } \\
\text { no associated in situ component }\end{array}$ & $\begin{array}{l}\text { Melanoma, } \\
\text { lymphoma, other }\end{array}$ \\
\hline
\end{tabular}

$E R$ estrogen receptor, $G I$ gastrointestinal, $N / C$ nuclear-to-cytoplasmic.

negative breast carcinoma. Melanoma should always be considered in the setting of a poorly differentiated, highgrade epithelioid neoplasm in the axilla or breast. Immunostains that label and support the diagnosis of melanoma include HMB45, Melan A, MITF, S-100, and Sox10 [22] (Fig. 5). S-100 and Sox 10 are more sensitive than HMB45, Melan A, and MITF for desmoplastic melanoma, so it is preferable to include S-100 and Sox10 in a targeted immunopanel to identify melanoma. However, this poses a significant diagnostic pitfall in the work-up of a high-grade $\mathrm{ER}^{-}$neoplasm, as both triple negative breast carcinoma and melanoma can be Sox $10^{+}$and S-100 $[10-15,23]$. Sox 10 and S-100 also both label granular cell tumor, which occurs in the breast [24]. In these settings, it is crucial to include at least one pan-cytokeratin immunostain (such as AE1/AE3, CK903 [34ße12], or Cam5.2), as triple negative breast carcinoma should show positive labeling for cytokeratin while melanoma is negative.

\section{Lung adenocarcinoma}

All histologic subtypes of lung cancer can metastasize to the breast, and lung adenocarcinoma in particular has morphologic overlap with both low-grade and high-grade breast carcinomas. Lung adenocarcinoma is identified by nuclear labeling for TTF-1 and cytoplasmic labeling for Napsin A $[3,19,20]$ (Fig. 6), which only rarely label breast carcinoma [25]. Metastatic lung adenocarcinoma should especially be considered in the setting of a well-differentiated, glandforming adenocarcinoma in the breast that is $\mathrm{ER}^{-}$, as the vast majority of low-grade breast carcinomas are $\mathrm{ER}^{+}$.
However, lung adenocarcinomas also label for ER [20] and GATA3 [7], so remembering to include TTF-1 (with or without Napsin A) is crucial in this differential.

\section{High-grade serous carcinoma}

The majority of high-grade serous carcinomas of gynecologic tract origin display micropapillary architecture and are $\mathrm{ER}^{+}$[3], features which overlap with micropapillary carcinoma of the breast. However, in contrast to $\mathrm{ER}^{+}$breast carcinoma, high-grade serous carcinoma is usually negative by immunohistochemistry for mammaglobin and GCDFP [26]. High-grade serous carcinoma is identified by nuclear labeling for PAX8 and WT-1 [3, 26] (Fig. 7), but neither of these immunostains is entirely specific. PAX8 also labels renal cell carcinoma, and both WT-1 and PAX8 label mesotheliomas, although these entities are generally morphologically dissimilar to micropapillary carcinoma. WT-1 also notably labels a subset of breast carcinomas, particularly the micropapillary special-type [27]; thus, PAX8 is more specific than WT-1 in distinguishing high-grade ovarian carcinoma from breast carcinoma [28]. However, PAX8 specificity does vary with the antibody clone used $[3,29]$. In the differential diagnosis of a micropapillary carcinoma in the breast or axilla, it is critical to include both markers of "mammary" origin (such as GATA3 or GCDFP) and "gynecologic tract" origin (such as PAX8).

\section{Prostatic adenocarcinoma}

Metastatic prostatic adenocarcinoma to the breast mimics primary breast carcinoma due to its glandular, cribriform, and papillary architecture. Prostatic adenocarcinoma is negative for ER, GATA3, GCDFP, and mammaglobin, but typically displays cytoplasmic labeling for PSA, apical and granular labeling for P501S, and nuclear labeling for NKX3.1 [3] (Fig. 8). NKX3.1 is an androgen-regulated tumor suppressor gene, and NKX3.1 immunohistochemistry is highly sensitive and specific for prostatic adenocarcinoma [3, 30]. NKX3.1 is particularly useful in identifying metastatic treatment-resistant and/or high-grade prostatic adenocarcinoma, which often loses PSA and P501S labeling. In addition, PSA labeling is seen in a significant number (20-40\%) of breast carcinomas [3]. Although NKX3.1 does label a small subset of breast carcinomas, particularly lobular carcinomas, $\mathrm{ER}^{+}$carcinomas, and androgen receptor positive carcinomas [31] (Fig. 9), NKX3.1 labeling in breast cancer is generally less intense and less diffuse than in prostate cancer. NKX3.1 immunohistochemistry is still useful to include in resolving this differential diagnosis. 

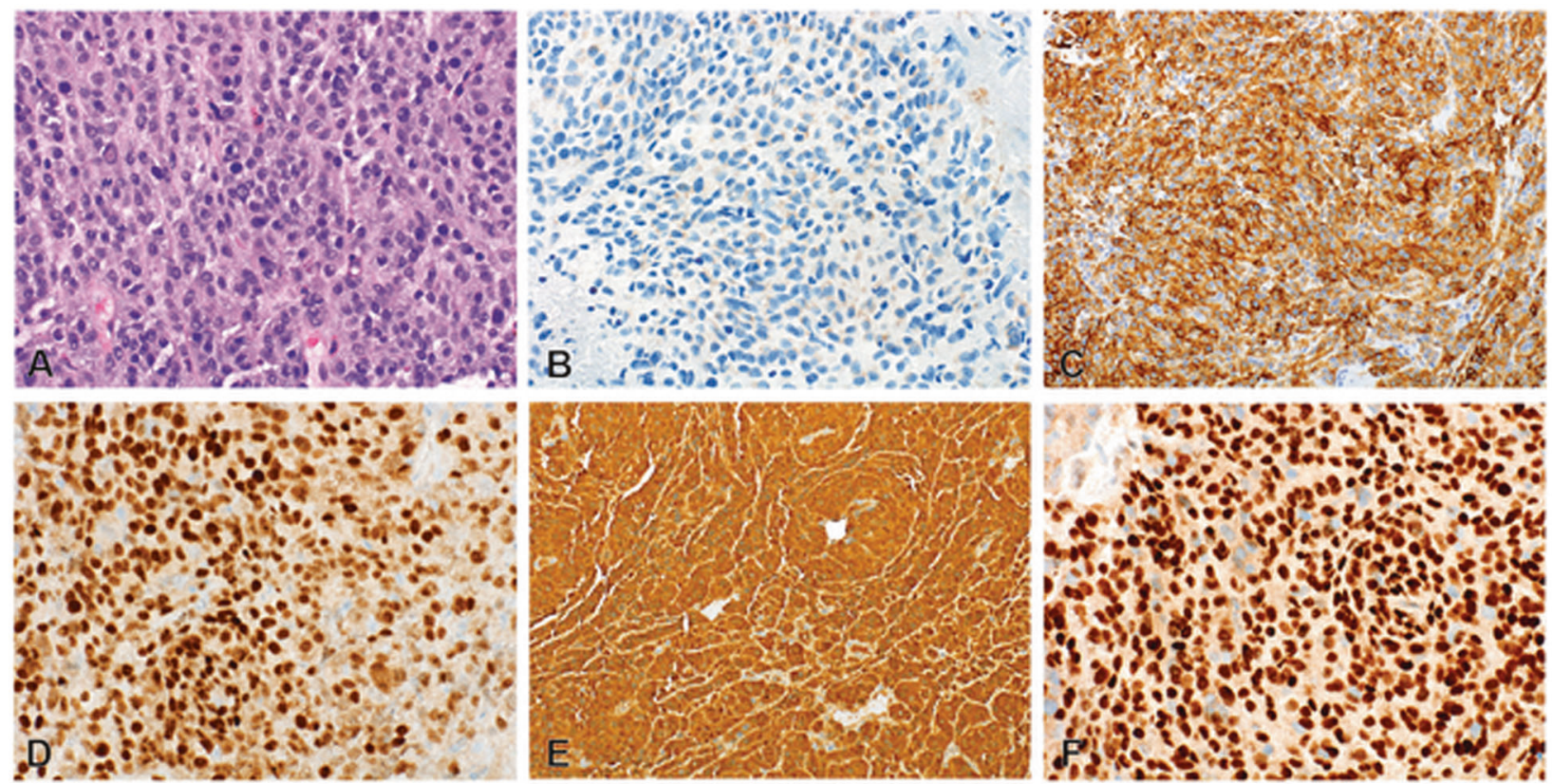

Fig. 5 Metastatic melanoma to the breast. Metastatic melanoma can display high nuclear grade, intranuclear inclusions, frequent mitotic activity, and melanin pigment (A). Melanomas are negative for pan-

cytokeratin (Cam5.2) (B), but can show diffuse labeling for cytoplasmic HMB45 (C), nuclear MITF (D), cytoplasmic and nuclear S$100(\mathbf{E})$, and nuclear Sox10 (F).
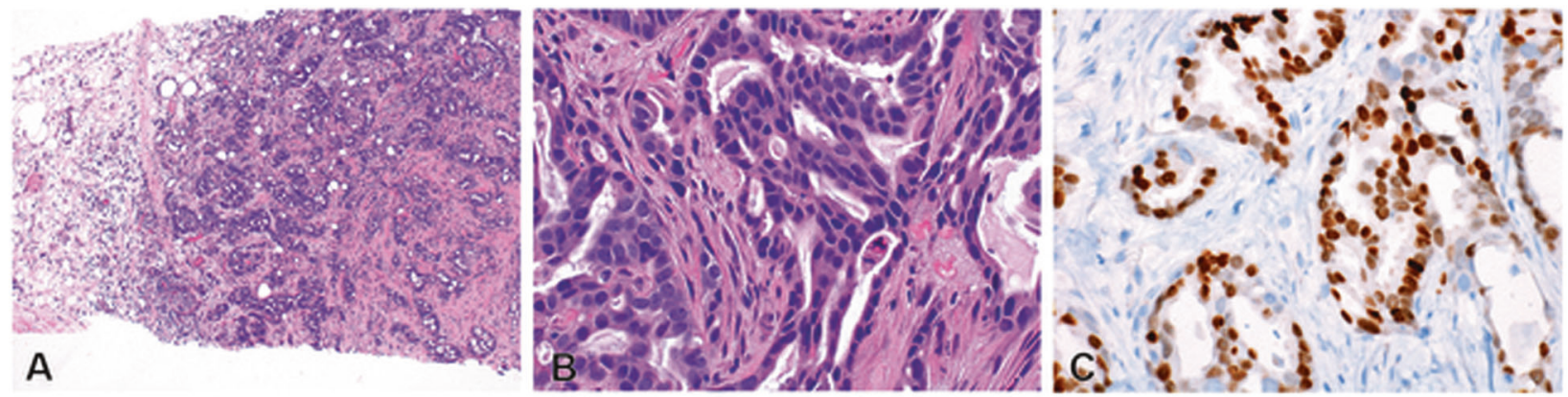
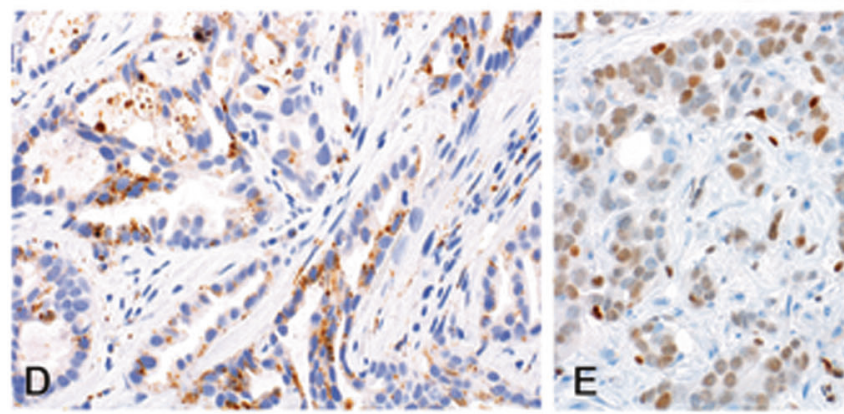

Fig. 6 Metastatic lung adenocarcinoma to the breast. Lung adenocarcinoma with well-formed glands, cribriform architecture, and desmoplasia (A, B) mimics breast carcinoma. Lung adenocarcinomas can be identified by labeling for nuclear TTF-1 (C) and cytoplasmic Napsin A (D); but, they can also label for nuclear GATA3 (E) and ER (F), which is a pitfall for breast carcinoma.

\section{Pancreatic adenocarcinoma}

Signet-ring cell and gland-forming adenocarcinoma metastatic to the breast from the gastrointestinal tract and pancreas mimic primary invasive lobular and ductal carcinomas, respectively. Gastrointestinal tract adenocarcinomas and many pancreatic adenocarcinomas are immunoreactive for CDX2 [3, 32] (Fig. 10), which has high specificity in this 
Fig. 7 Metastatic high-grade ovarian serous carcinoma to the breast. High-grade serous carcinoma with micropapillary architecture (A) mimics breast micropapillary carcinoma, both of which can be $\mathrm{ER}^{+}$positive (not shown). However, highgrade serous carcinoma is negative for mammaglobin (B) but shows strong and diffuse nuclear labeling for Pax8 (C) and WT-1 (D).
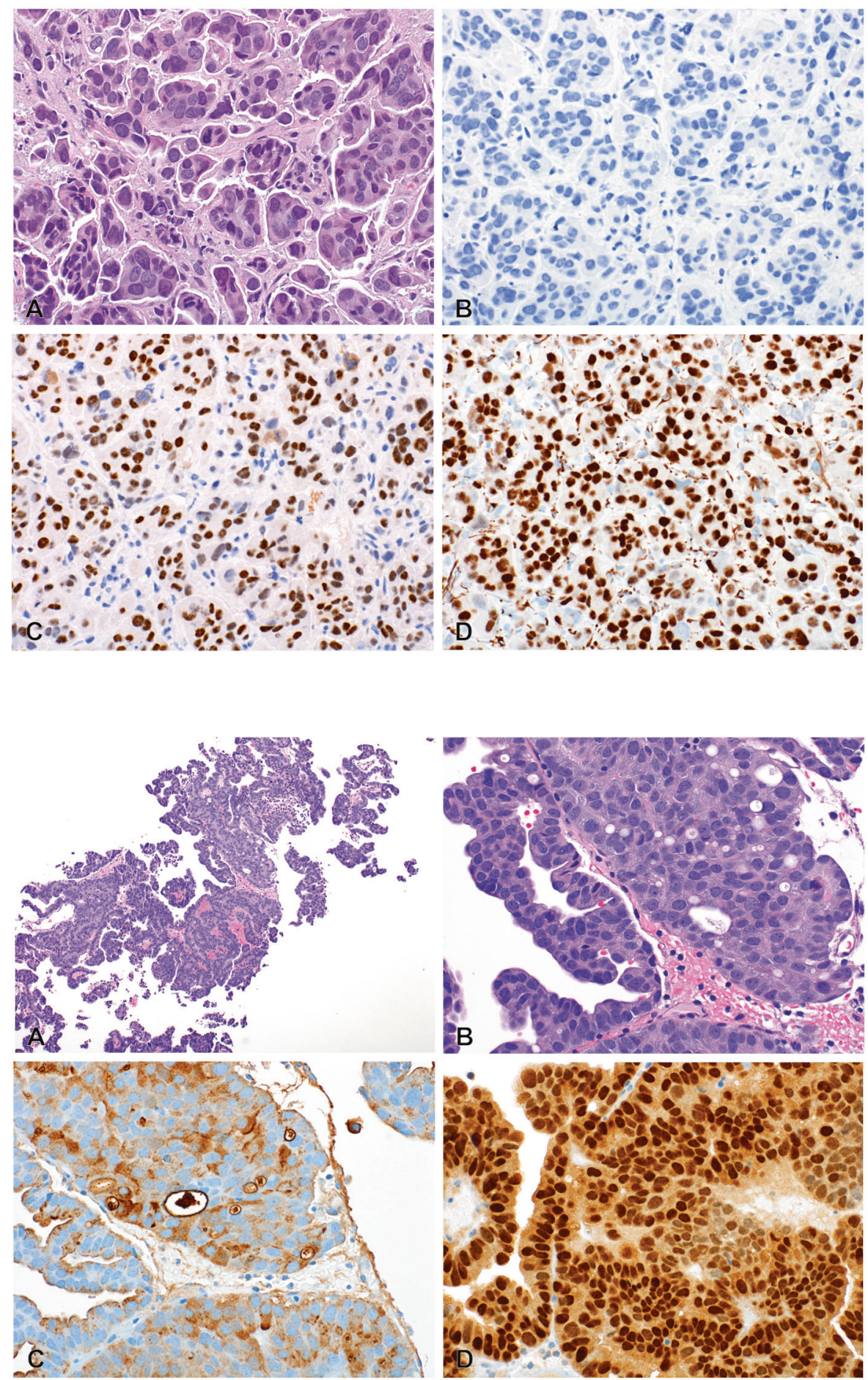

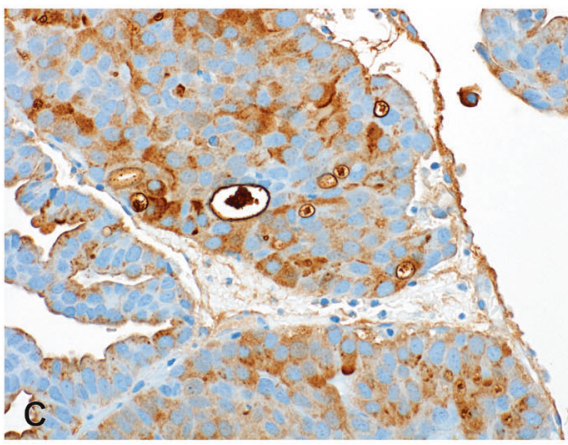

Fig. 8 Metastatic prostatic adenocarcinoma to the breast. Prostatic adenocarcinoma displays glandular, cribriform, and papillary architecture $(\mathbf{A}, \mathbf{B})$ and mimics primary breast carcinoma. Prostatic adenocarcinoma is typically positive for cytoplasmic PSA (C), nuclear NKX3.1 (D), and P501S (not shown). setting and rarely labels breast carcinomas. In addition, approximately half of pancreatic adenocarcinomas display loss of nuclear labeling for SMAD4/DPC4, reflecting mutations and deletions in the SMAD4 (DPC) tumor suppressor gene $[19,33]$, whereas loss is very rarely reported in breast carcinoma [33]. Gastrointestinal tract and pancreatic adenocarcinomas are typically negative for ER, GCDFP, and mammaglobin. However, GATA3 labeling is seen in a subset of pancreatic adenocarcinomas [7], and immunohistochemistry for GATA3 alone is not sufficient to resolve the differential diagnosis of pancreatic adenocarcinoma and breast carcinoma. As always, a panel approach is necessary, and immunohistochemistry for CDX2 and ER should also be included in this differential. 
Fig. 9 NKX3.1 in breast carcinoma. Invasive lobular carcinoma, characterized by loosely cohesive cells in singlefile or single-cell arrangement (A), can display diffuse nuclear NKX3.1 labeling (B). Male invasive ductal carcinoma, characterized by variable gland formation (C), can also display nuclear NKX3.1 labeling (D).
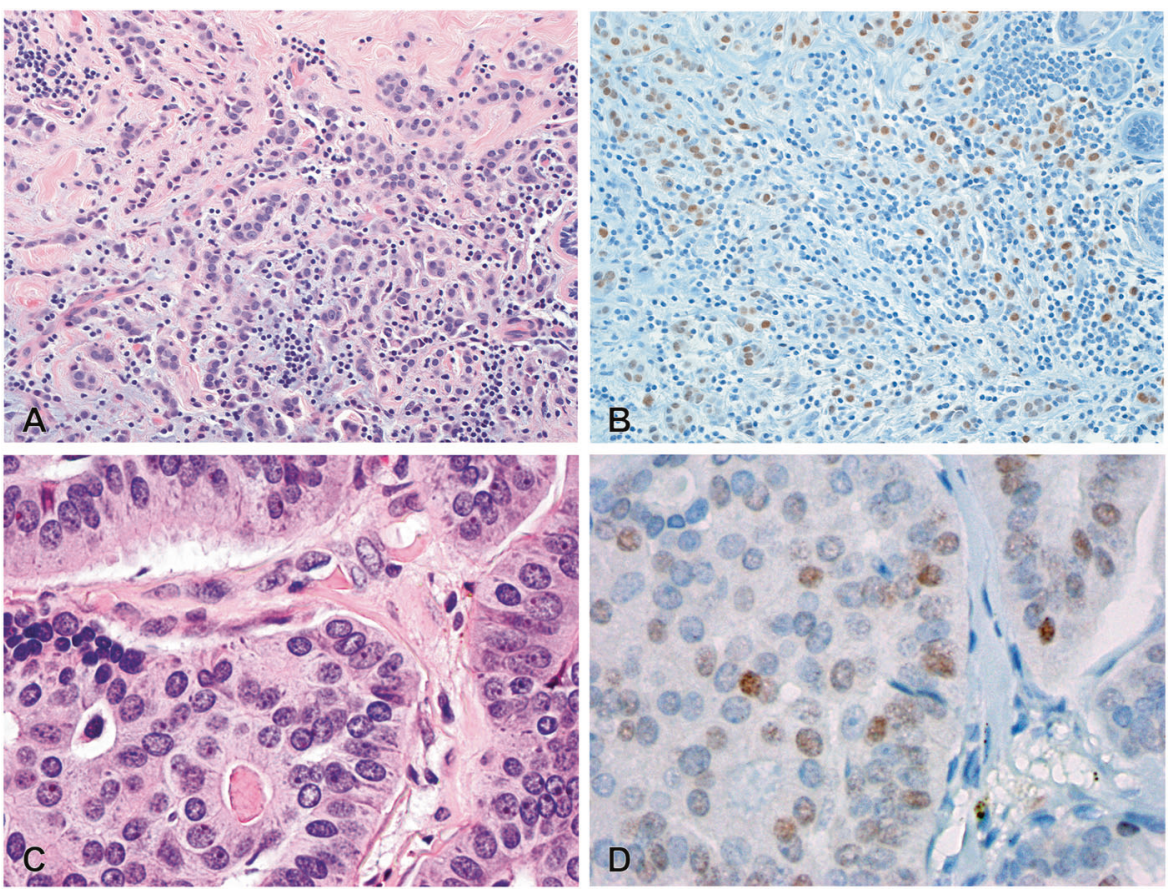

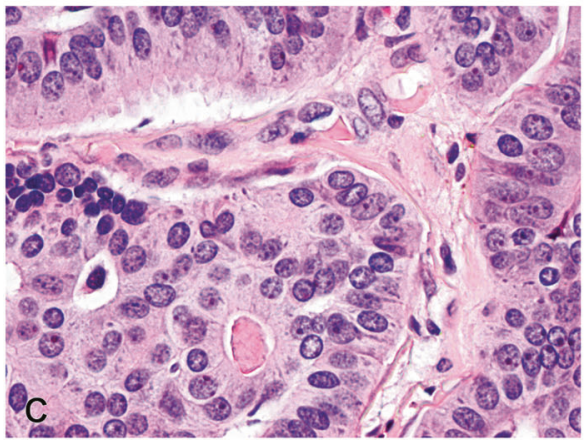

Fig. 10 Metastatic pancreatic adenocarcinoma to the breast. Pancreatic adenocarcinoma displays variable gland formation and desmoplasia (A), mimicking breast carcinoma. Pancreatic adenocarcinomas are negative for mammaglobin (B), and a subset show nuclear CDX2 labeling (C) and loss of nuclear SMAD4/DPC4 labeling, with stromal cell labeling as an internal control (D).

\section{Immunohistochemistry for specific genomic drivers in special-type carcinomas}

Molecular sequencing and cancer cytogenetics continue to deepen our understanding of the specific genomic drivers of cancers, leading to refinement of tumor classification across organ systems and sometimes resulting in the development of targeted therapies. Novel immunohistochemistry markers have emerged as surrogates for specific molecular changes in several special-type breast carcinomas, including adenoid cystic carcinoma, secretory carcinoma, and tall cell carcinoma with reversed polarity (TCCRP) (Table 3). Use of these immunostains aids in the correct classification of these breast 
Table 3 Immunohistochemistry for molecular drivers of specialtype breast carcinomas.

\begin{tabular}{lll}
\hline Special-type breast carcinoma & Most-common molecular alteration & Immunohistochemistry \\
\hline Adenoid cystic carcinoma & $\begin{array}{l}t(6 ; 9) \text { translocation, resulting in the MYB- } \\
\text { NFIB gene fusion }\end{array}$ & MYB \\
Secretory carcinoma & $t(12 ; 15)$ translocation resulting in ETV6- & Pan-TRK \\
& $N T R K 3$ gene fusion & \\
Tall cell carcinoma with reversed & $I D H 2$ p.ARG172 hotspot mutation & IDH2 \\
polarity (TCCRP) & & \\
\hline
\end{tabular}

Fig. 11 MYB in adenoid cystic carcinoma. Breast adenoid cystic carcinoma displays dual epithelial and myoepithelial cells arranged in solid, tubular, or cribriform structures (a) and displays strong and diffuse nuclear MYB labeling. B This reflects MYB protein accumulation, most often due to a $t(6 ; 9)$ translocation and $M Y B$ $N F I B$ fusion. Triple negative ductal carcinomas also display tubules, nests, or sheets of basaloid cells $(\mathbf{C})$, but only focal MYB labeling (D).
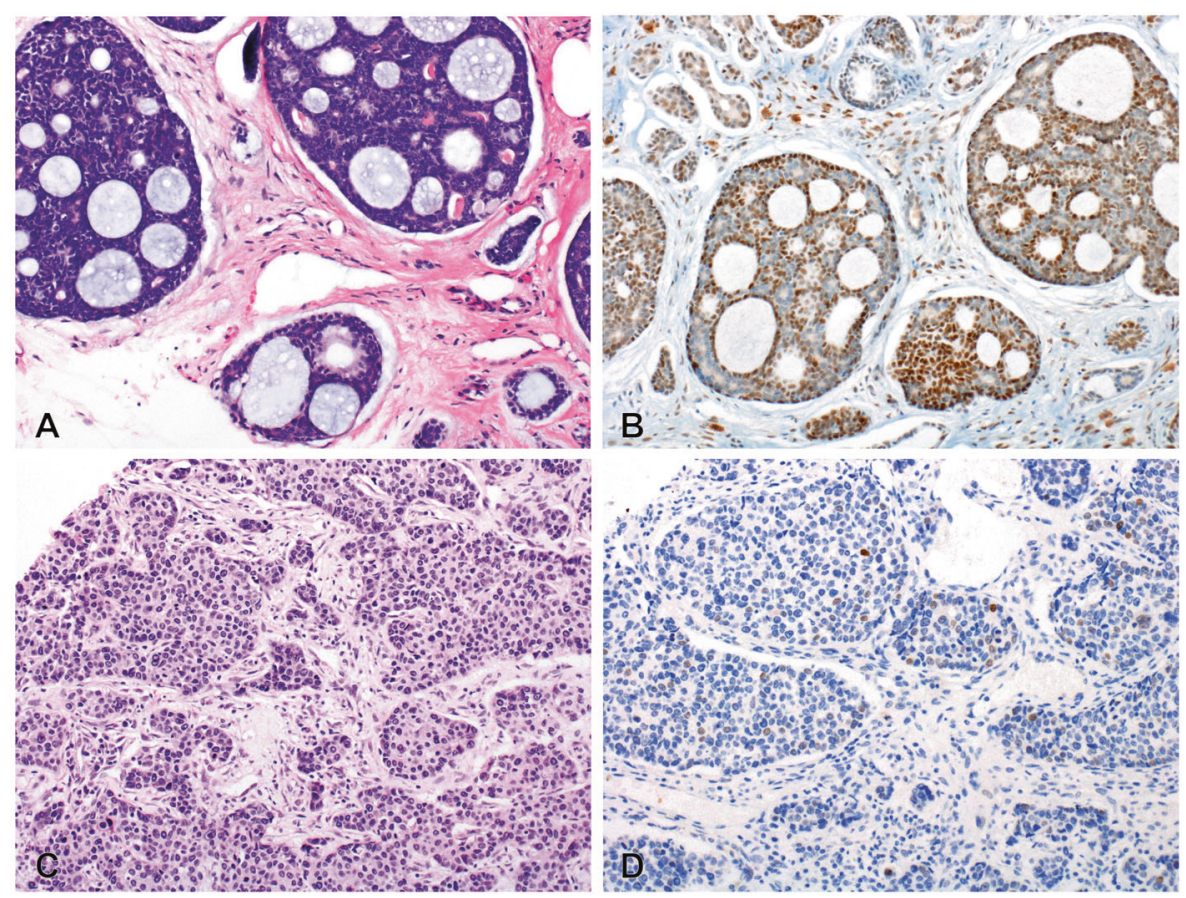

carcinomas, often at a lower cost and quicker turnaround time than the corresponding molecular testing.

\section{Adenoid cystic carcinoma}

Breast adenoid cystic carcinoma is a rare special-type carcinoma that has the same morphologic, immunophenotypic, and molecular features as its salivary gland counterpart [34]. The morphologic features, with or without immunostains to highlight the dual cell components, are often sufficient to identify classic adenoid cystic carcinoma. However, ancillary studies may be required in cases with solid or highgrade patterns that mimic basal-like triple negative ductal carcinoma. The majority of breast adenoid cystic carcinoma display a $t(6 ; 9)$ translocation, resulting in the $M Y B-N F I B$ gene fusion [35]. MYLB1 rearrangements and $M Y B$ amplification have also been demonstrated in cases that lack $t$ (6;9) [36]. These alterations can be detected by molecular sequencing, fluorescence in situ hybridization, chromogenic in situ hybridization, or immunohistochemistry. In the breast, MYB immunohistochemistry is sensitive and specific for adenoid cystic carcinoma [37], with strong and diffuse nuclear labeling (Fig. 11). Only rare MYB labeling seen in triple negative breast carcinomas (Fig. 11) and other entities in the differential diagnosis [37]. MYB immunohistochemistry is helpful to confirm the diagnosis of breast adenoid cystic carcinoma.

\section{Secretory carcinoma}

Breast secretory carcinoma is another rare special-type carcinoma that has the same morphologic, immunophenotypic, and molecular features its salivary gland counterpart [38]. Secretory carcinoma is often $\mathrm{ER}^{-}$and HER-2 ${ }^{-}$, but has a unique immunophenotypic profile among triple negative breast carcinomas, because it diffusely labels for mammaglobin and GCDFP (Fig. 12). In addition, secretory carcinoma is another breast carcinoma type that displays strong and diffuse Sox10 and S-100 labeling (Fig. 12). Secretory carcinoma displays a $t(12 ; 15)$ translocation, resulting in the ETV6-NTRK3 gene fusion $[38,39]$. In the breast, this gene fusion is unique to secretory carcinoma; however, it is seen in 
Fig. 12 Immunohistochemistry in secretory carcinoma. Breast secretory carcinoma is characterized by solid, tubular, and cribriform arrangements of epithelioid cells with abundant eosinophilic cytoplasm, prominent nucleoli, and intraluminal secretions $(\mathbf{A}, \mathbf{B})$. Although usually triple negative, they display diffuse labeling for GCDFP (C), S-100 (D), and mammaglobin (not shown).
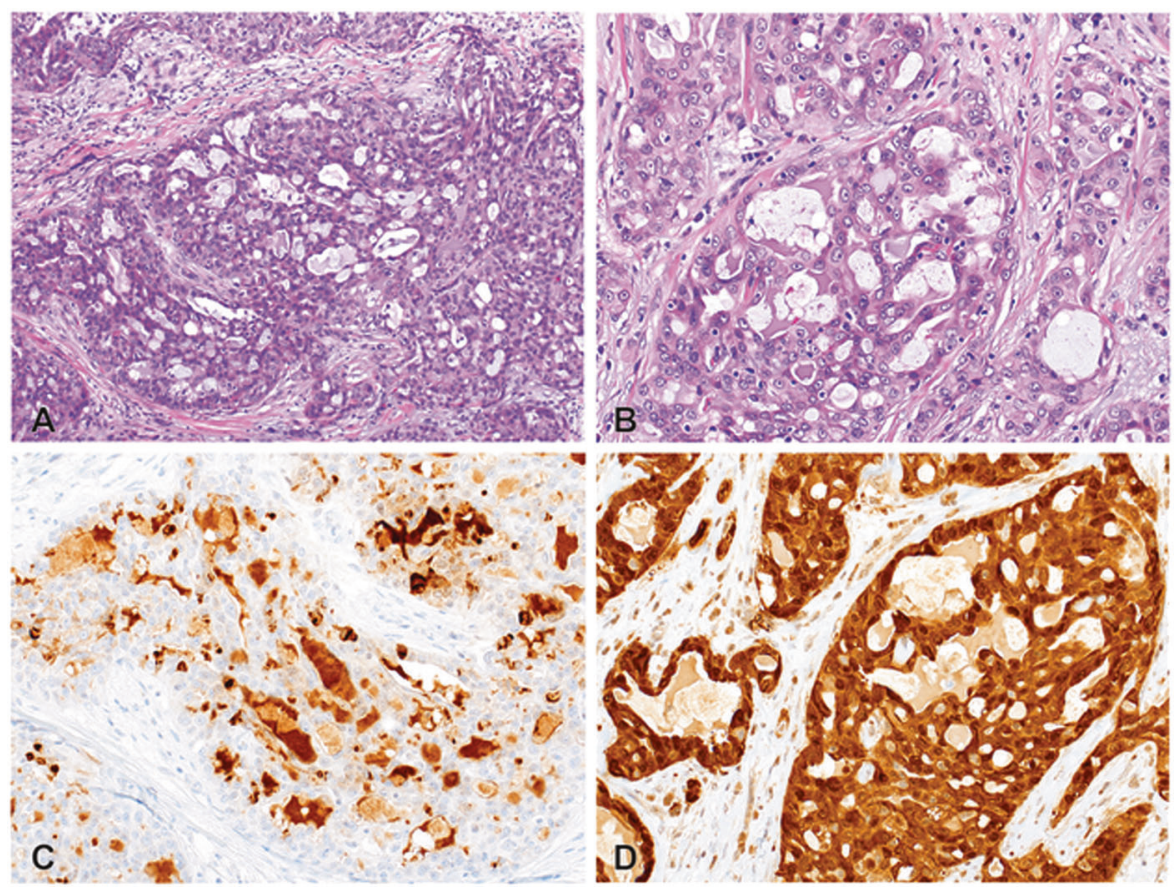

a variety of other extramammary tumor types including congenital infantile fibrosarcoma, cellular mesoblastic nephroma, gliomas, leukemias, and other carcinomas [40]. Molecular sequencing or fluorescence in situ hybridization can demonstrate this translocation and confirm the diagnosis. Pan-TRK immunohistochemistry is a novel surrogate marker for NTRK family gene rearrangements across tumor types [41]. Among breast carcinomas, pan-TRK labeling is sensitive and specific for breast secretory carcinoma [42]. PanTRK immunohistochemistry is emerging as a useful diagnostic adjunct in this setting.

\section{Tall cell carcinoma with reversed polarity (TCCRP)}

TCCRP is a rare special-type carcinoma characterized by solid and papillary architecture, columnar cells with ample eosinophilic cytoplasm, and apically oriented nuclei displaying similar nuclear features as papillary thyroid carcinoma [43] (Fig. 13). Reflecting its morphologic features, TCCRP has previously been called "solid papillary carcinoma with reverse polarity" and "breast tumor resembling the tall cell variant of papillary thyroid carcinoma." Although exceedingly rare, TCCRP is worth mentioning because it is characterized by an IDH2 p.ARG172 hotspot mutation [43, 44], which is also seen in infiltrating gliomas and other tumor types [45]. Immunohistochemistry for mutant IDH2 shows cytoplasmic labeling in TCCRP (Fig. 13) and, in the breast, is sensitive and specific for TCCRP [46, 47]. In addition, IDH2 immunohistochemistry is already in routine use in many pathology laboratories for the diagnostic work-up and classification of high-grade gliomas. IDH2 immunohistochemistry is a useful surrogate for the IHD2 p.ARG172 hotspot mutation when TCCRP enters the differential diagnosis.

\section{Immunohistochemistry for PD-L1 as an immune biomarker}

Immunohistochemistry for PD-L1 is an emerging, yet imperfect, predictive biomarker for use of immune checkpoint inhibitors in breast carcinoma. To date, the Food and Drug Administration (FDA) has designated three PD-L1 assays as "companion diagnostics" to determine patient eligibility for use of specific checkpoint inhibitors in their FDA-approved indications (Table 4) [48-51], including the Ventana PD-L1 (S142) assay for use in triple negative breast carcinoma. Implementation and interpretation of PD-L1 immunohistochemistry are rife with caveats, differ across tumor types, and vary between checkpoint inhibitors. Cancer immunotherapy, companion diagnostics, and predictive biomarker development are also evolving rapidly [49, 50, 52, 53]. The indications and testing parameters will in breast cancer undoubtedly change as we continue to learn more about breast cancer immuno-oncology and explore the optimal biomarker(s) for patient selection.

\section{Checkpoint inhibition in advanced breast cancer}

In March 2019, the PD-L1 inhibitor atezolizumab, in combination with nab-paclitaxel chemotherapy, was granted accelerated FDA approval for use in ${\mathrm{PD}-\mathrm{L}^{+}}^{+}$advanced 
Fig. 13 IDH2 in tall cell carcinoma with reversed polarity (TCCRP). The rare special-type carcinoma, TCCRP, is characterized by columnar cells with eosinophilic cytoplasm, apically oriented nuclei, and irregular nuclear contours with solid and papillary architecture (A-C). They display cytoplasmic labeling for mutant IDH2 protein $(\mathbf{D}$, image courtesy of Dr Doreen Palsgrove), reflecting the presence of IDH2 p.ARG172 hotspot mutations.

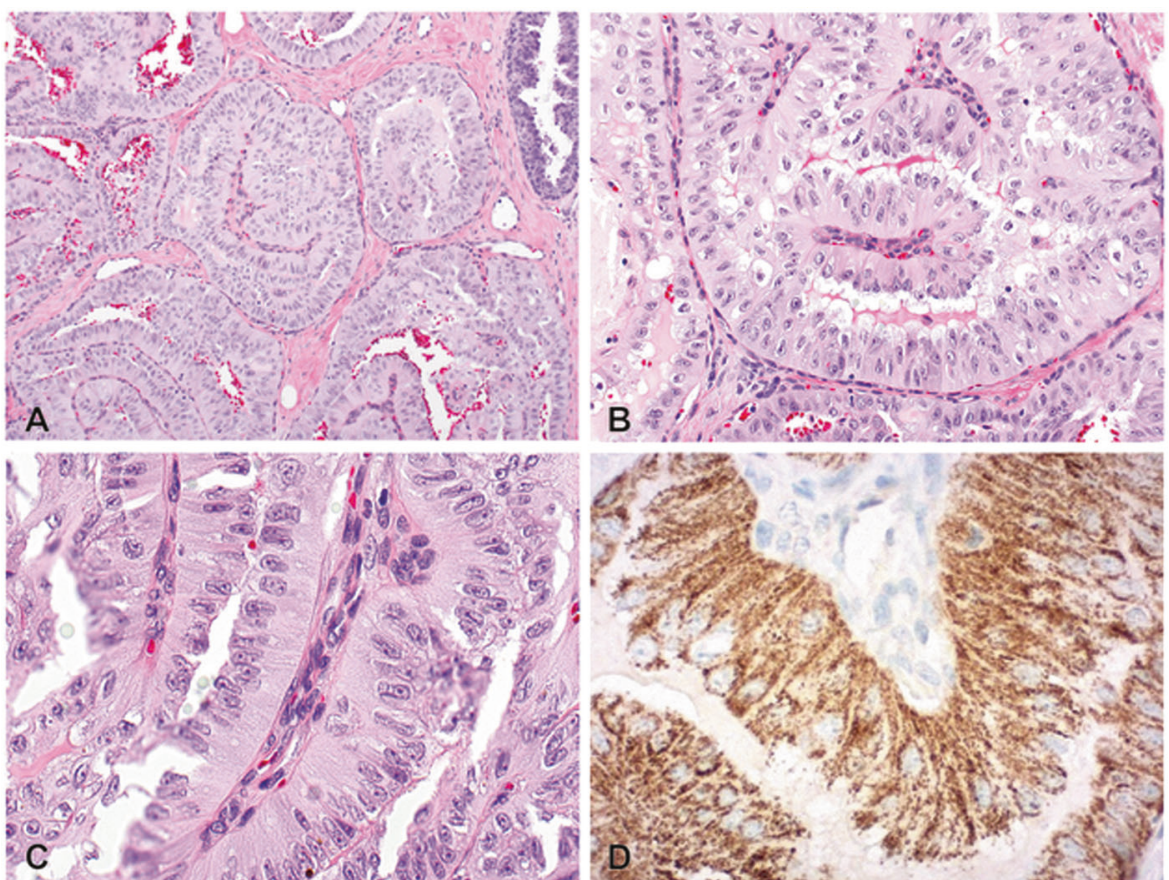

triple negative breast carcinoma [54]. The approval of atezolizumab was a watershed moment for breast cancer therapy, as it represented not only the first immune checkpoint inhibitor to be approved specifically in breast carcinoma but also the first targeted therapy for use in triple negative breast carcinoma [55]. The approval was based upon the results of the IMPassion 130 phase 3 clinical trial [56], which demonstrated significantly longer progressionfree survival (PFS) (2.2-month improvement) and a clinically meaningful improvement in overall survival (OS) (7month improvement) in patients with $\mathrm{PD}-\mathrm{L1}^{+}$advanced triple negative breast carcinoma who received with atezolizumab and nab-paclitaxel chemotherapy. Multiple clinical trials with other PD-1/PD-L1 checkpoint inhibitors are ongoing $[55,57,58]$ and will hopefully lead to additional drug approvals in the near future.

\section{PD-L1 as a companion diagnostic in breast cancer}

PD-L1 immunohistochemistry is a required companion diagnostic for use of atezolizumab in advanced triple negative breast cancer [49, 54, 59] (Table 4). The FDA approval states that PD-L1 status in breast cancer can be determined with any FDA-approved test [54]. To date, the only PD-L1 test with FDA approval for use in breast carcinoma is the Ventana PDL1 (S142) assay, which utilizes the PD-L1 antibody clone SP142 that was used in the IMPassion130 clinical trial $[51,56]$. This assay is different from the PD-L1 IHC 22C3 Pharm Dx and PD-L1 IHC 28-8 assays, which utilize the PDL1 antibody clones $22 \mathrm{C} 3$ and $28-8$ on a Dako platform and are FDA-approved as companion diagnostics in other cancer types [49, 51] (Table 4). The Ventana PD-L1 (SP263) assay is commercially available as a complementary diagnostic [59], but does not currently have FDA approval as a companion diagnostic. The Ventana PD-L1 (SP142) assay uses the Immune Cell (IC) Score criteria for evaluating PD-L1 status in triple negative breast carcinoma [60] (Table 5). PD-L1 status is determined as the percentage tumor area occupied by PD-L1 ${ }^{+}$ICs, with a scoring threshold of $1 \%$ to determine eligibility for therapy with atezolizumab. That is, a triple negative breast carcinoma is considered "PD-L1 positive" if the tumor displays: PD- $1^{+}$ICs occupying $\geq 1 \%$ of the tumor area (Fig. 14). "ICs" refer to all ICs, not just the tumor infiltrating lymphocytes (TILs) but also the plasma cells, neutrophils, and macrophages. The percentage score is not the percentage of ICs that label, but rather the percentage of the tumor area occupied by ICs that label for PD-L1. This scoring system is different from the tumor proportion score, tumor cell (TC) score, and combined positive score that are used for other agents in other tumor types (Table 4).

\section{Specimen considerations for PD-L1 immunohistochemistry}

The Ventana PD-L1 (S142) assay is not validated for use in cytology cell blocks or smears, nor on decalcified specimens [60]. PD-L1 as a companion diagnostic can be performed on either the primary tumor or a metastatic tumor. It is not entirely clear how the immune microenvironment of a primary tumor predicts the immunotherapy response of a metastatic tumor, which occurs after a time interval and/or 
Table 4 PD-L1

immunohistochemistry

companion diagnostics.

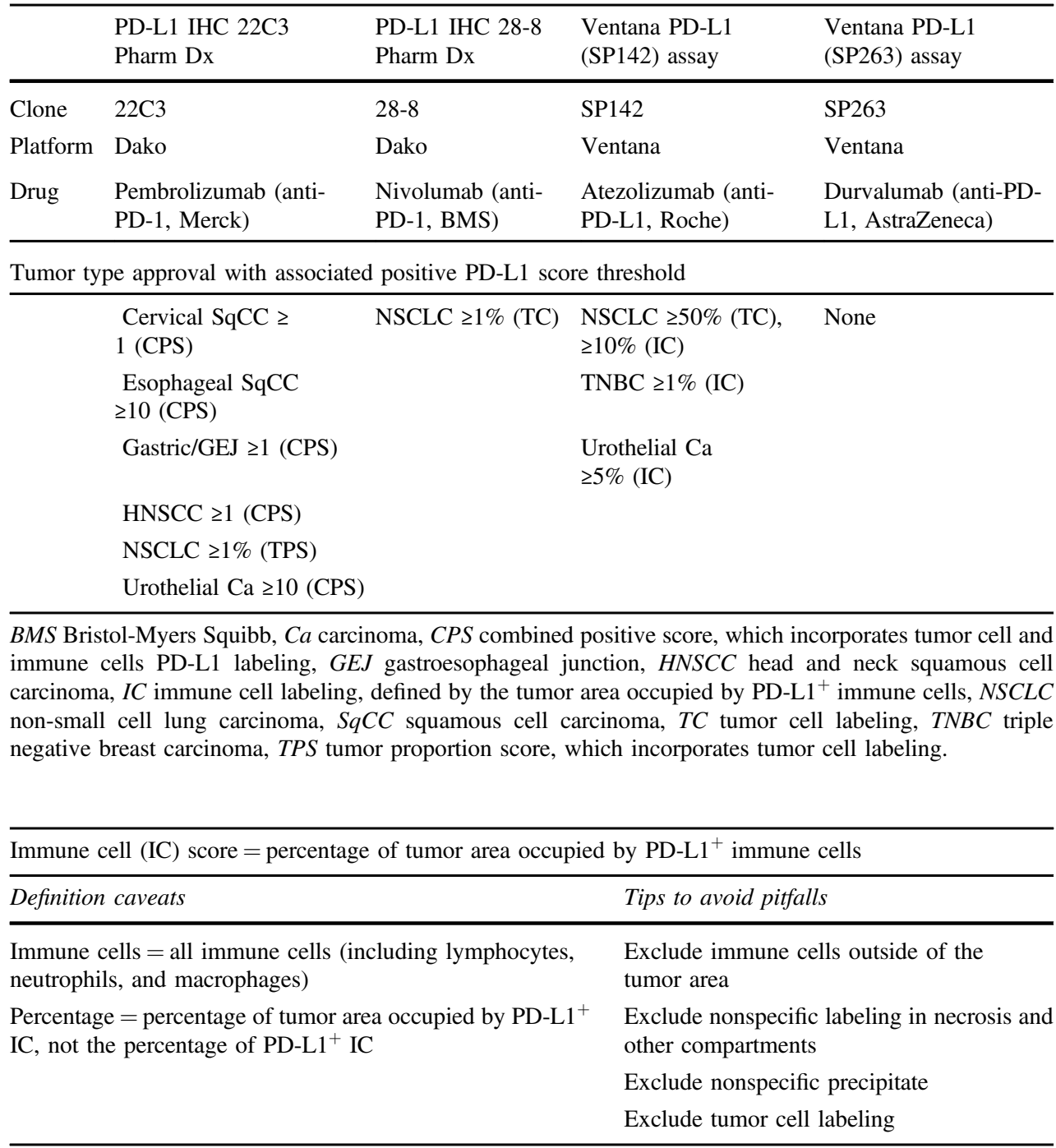

Table 5 Scoring criteria for PDL1 immunohistochemistry in triple negative breast cancer. the administration of other systemic chemotherapies, but a positive result in either the primary or metastatic tumor renders a patient eligible for the approved therapy [54, 56]. However, the sample type and location will impact the PDL1 result. Metastatic tumors can have different PD-L1 expression than the primary tumor [61] and are in general less inflamed (e.g., contain lower numbers of ICs) than primary tumors $[62,63]$. Certain metastatic niche locations, such as liver, are less inflamed than others, such as lung [64]. Sites with lower overall numbers of ICs are less likely to have any ICs, let alone PD-L1 ${ }^{+}$ICs, occupying $\geq 1 \%$ of the tumor area. For this reason, PD-L1 testing on metastatic tumors to the liver should be avoided.

\section{Pitfalls in PD-L1 interpretation}

The reproducibility of PD-L1 scoring is a concern across tumor types, but particularly in breast cancer. Although scoring PD-L1 labeling in TCs has been shown to be reproducible [65], there is substantial debate on the reproducibility of scoring PD-L1 labeling in ICs [65-68] and particularly in accurately distinguishing between $<1 \%$ and $1 \%$ tumor area. Use of standardized pathologist training, pictorial interpretation guides, or image analysis software could potentially improve reproducibility in IC PD-L1 scoring, but additional systematic studies are needed. In addition, PD-L1 labeling in breast cancer should be scored only in ICs - not TCs - and only in ICs located within the borders of the invasive carcinoma cells. IC scoring of metastases to lymph nodes can be particularly problematic, as a distinction needs to be made between the "tumor-associated" ICs and the normal resident lymphocytes. The presence of associated desmoplasia around the carcinoma nests can help define the tumor area in this setting. Nonspecific PD-L1 labeling can be seen in areas of necrosis (Fig. 15) and as nonspecific precipitates, both of which should be excluded from scoring. 
Fig. 14 PD-L1 in breast

cancer. PD-L1 in triple negative breast carcinoma is assessed with the immune cell (IC) score, equating to the percentage tumor area occupied by PD-L1 ${ }^{+}$ immune cells, using the Ventana PD-L1 (SP142) assay. A primary triple negative breast carcinoma with minimal inflammatory infiltrate $(\mathbf{A})$ is PD-L1 negative due to a PD-L1 immune cell (IC) score of $0 \%$ (B); nonspecific, punctate cytoplasmic labeling is seen within the tumor cells. A primary triple negative breast carcinoma with prominent inflammatory infiltrate $(\mathbf{C})$ is $P D-L 1$ positive due to an IC score of $20-25 \%$ (D), which falls above the IC positivity threshold of $\geq 1 \%$.
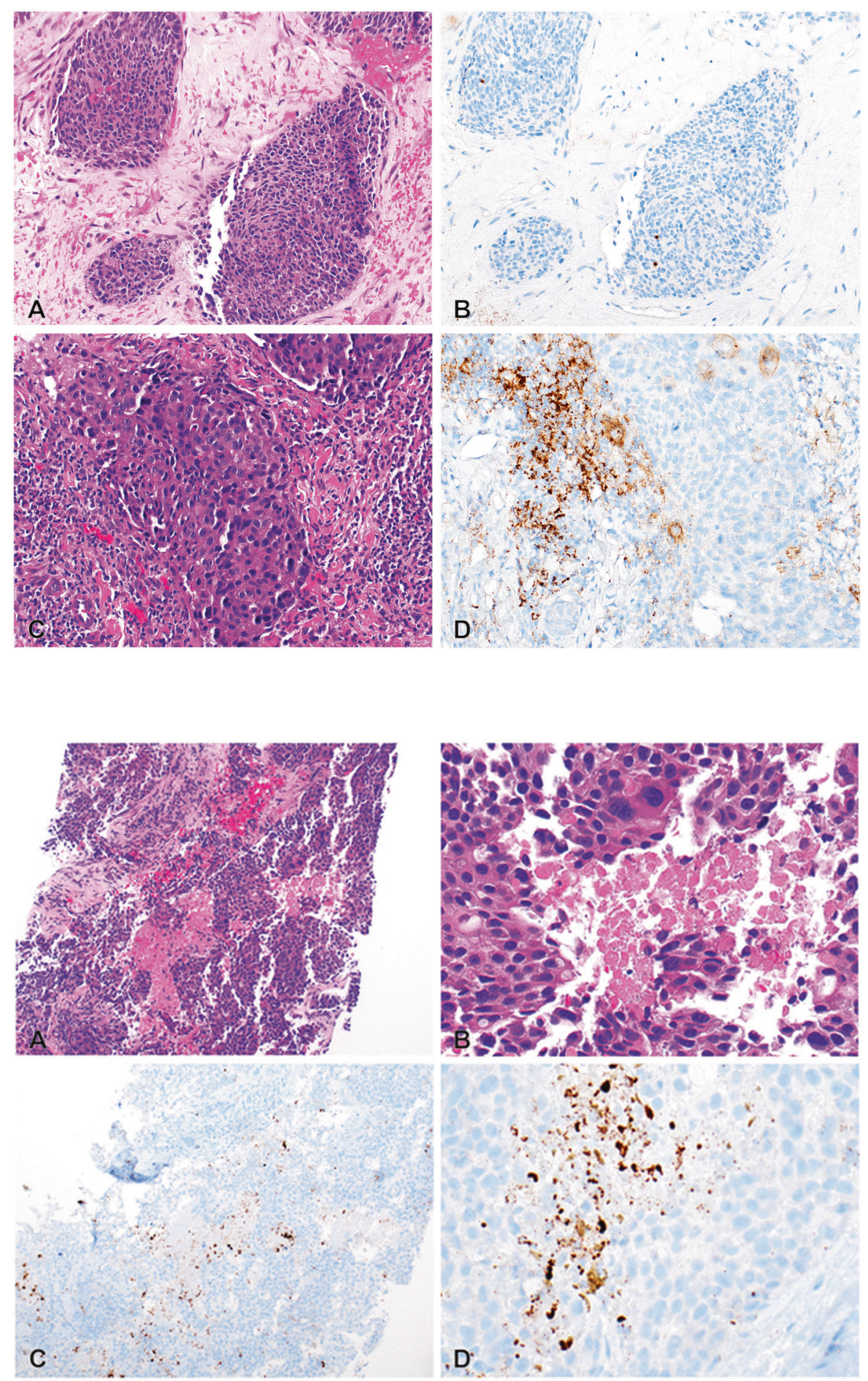

Fig. 15 Nonspecific PD-L1 labeling. A primary triple negative breast carcinoma displays abundant cellular necrosis (A, B), which shows nonspecific PD-L1 labeling on the Ventana PD-L1 (SP142) assay $(\mathbf{C}, \mathbf{D})$. The tumor is $P D$ $L 1$ negative, due to the presence of PD-L1 ${ }^{+}$immune cells in $<1 \%$ of the total tumor area (i.e., an immune cell (IC) score of $<1 \%$ ). addition, the different PD-L1 assays have different sensitivity for PD-L1. The individual PD-L1 antibody clones SP142, SP263, 22C3, and 28-8 have equal sensitivity for PD-L1 when used with identical assays (i.e., testing steps) [70], but the Ventana PD-L1 (SP142) assay (i.e., the SP142 antibody run with the Ventana assay platform) is less sensitive for PD-L1 than the other antibodies and their associated assays [71-74]. This lower sensitivity is thus 
attributable to the assay testing methods and parameters that reportedly optimize the specificity of Ventana PD-L1 (SP142) assay for IC labeling [68]. Practically, this means that the Ventana PD-L1 (SP142) assay is not directly interchangeable with the PD-L1 IHC 22C3 Pharm Dx, PDL1 IHC 28-8 Pharm Dx, or Ventana PD-L1 (S263) assays, as the latter three will classify more tumors as PD-L1 ${ }^{+}$than the Ventana PD-L1 (SP142) assay. Post hoc analysis of the IMPassion130 trial patients whose tumors are PD-L1 ${ }^{+}$ (IC $\geq 1 \%$ ) by SP263 or $22 \mathrm{C} 3$, but PD-L1 ${ }^{-}$by the Ventana PD-L1 (SP142) assay, showed that these patients do not demonstrate the same benefits in PFS and OS with atezolizumab [75]. To fully validate the use of PD-L1 IHC 22C3 Pharm Dx, PD-L1 IHC 28-8 Pharm Dx, or Ventana PD-L1 (S263) assays in this setting, they should be performed on the IMPassion130 clinical trial tumors to determine the percentage scoring cutoff at which equal predictive value is reached as with the Ventana PD-L1 (SP142) assay. To date, the data are unavailable.

\section{Emerging and future biomarker identification}

PD-L1 is a valuable but imperfect predictive biomarker. Favorable responses to PD-1/PD-L1 checkpoint inhibition are still seen in a subset of patients whose tumors lack PDL1 labeling [50], and additional studies are needed to identify and further refine the optimal biomarker(s) for use in breast cancer immunotherapy. Future biomarker profiles for immunotherapy will most likely consist of several components, possibly incorporating $\mathrm{CD}^{+}$counts, TILs scores, genomic alterations, or myriad unknown factors into the current immunohistochemistry biomarker profile of $\mathrm{ER}^{-} /$ HER-2 $2^{-} /$PD-L $^{+}$[53]. This is just one of many exciting avenues to explore in breast cancer immuno-oncology.

\section{Conclusion}

Immunohistochemistry is an essential component of diagnostic pathology. Use of a targeted immunopanel can aid in classification of a carcinoma as of breast origin and in identification of metastases to the breast. Novel immunostains serve as surrogates for molecular changes underlying special-type breast carcinomas and include the use of MYB in adenoid cystic carcinoma, pan-TRK in secretory carcinoma, and IDH2 in TCCRP. PD-L1 immunohistochemistry is a novel but imperfect biomarker for PD-1/PD-L1 checkpoint inhibition in triple negative breast carcinoma, and the identification and implementation of novel biomarker profiles will be required to evolve with the rapidly changing landscape of breast cancer immunotherapy.
Acknowledgements The author thanks Dr Doreen Palsgrove (University of Texas Southwestern, Dallas, TX) for providing the photomicrograph of IDH2 labeling in tall cell carcinoma with reversed polarity.

\section{Compliance with ethical standards}

Conflict of interest ACM reports research funding from Bristol-Myers Squibb and Genentech, and is a consultant to Bristol-Myers Squibb and Roche/Genentech.

Publisher's note Springer Nature remains neutral with regard to jurisdictional claims in published maps and institutional affiliations.

\section{References}

1. Bhargava R, Beriwal S, Dabbs DJ. Mammaglobin vs GCDFP-15: an immunohistologic validation survey for sensitivity and specificity. Am J Clin Pathol. 2007;127:103-13.

2. Luo MH, Huang YH, Ni YB, Tsang JY, Chan SK, Shao MM, et al. Expression of mammaglobin and gross cystic disease fluid protein-15 in breast carcinomas. Hum Pathol. 2013;44:1241-50.

3. Conner JR, Hornick JL. Metastatic carcinoma of unknown primary: diagnostic approach using immunohistochemistry. Adv Anat Pathol. 2015;22:149-67.

4. Krings G, Nystrom M, Mehdi I, Vohra P, Chen YY. Diagnostic utility and sensitivities of GATA3 antibodies in triple-negative breast cancer. Hum Pathol. 2014;45:2225-32.

5. Asch-Kendrick R, Cimino-Mathews A. The role of GATA3 in breast carcinomas: a review. Hum Pathol. 2016;48:37-47.

6. Kouros-Mehr H, Slorach EM, Sternlicht MD, Werb Z. GATA-3 maintains the differentiation of the luminal cell fate in the mammary gland. Cell. 2006;127:1041-55.

7. Miettinen M, McCue PA, Sarlomo-Rikala M, Rys J, Czapiewski P, Wazny K, et al. GATA3: a multispecific but potentially useful marker in surgical pathology: a systematic analysis of 2500 epithelial and nonepithelial tumors. Am J Surg Pathol. 2014;38: 13-22.

8. Cimino-Mathews A, Subhawong AP, Illei PB, Sharma R, Halushka MK, Vang R, et al. GATA3 expression in breast carcinoma: utility in triple-negative, sarcomatoid, and metastatic carcinomas. Hum Pathol. 2013;44:1341-9.

9. Mollaaghababa R, Pavan WJ. The importance of having your SOX on: role of SOX10 in the development of neural crestderived melanocytes and glia. Oncogene. 2003;22:3024-34.

10. Miettinen M, McCue PA, Sarlomo-Rikala M, Biernat W, Czapiewski P, Kopczynski J, et al. Sox10-a marker for not only schwannian and melanocytic neoplasms but also myoepithelial cell tumors of soft tissue: a systematic analysis of 5134 tumors. Am J Surg Pathol. 2015;39:826-35.

11. Nonaka D, Chiriboga L, Rubin BP. Sox10: a pan-schwannian and melanocytic marker. Am J Surg Pathol. 2008;32:1291-8.

12. Cimino-Mathews A, Subhawong AP, Elwood H, Warzecha HN, Sharma R, Park BH, et al. Neural crest transcription factor Sox 10 is preferentially expressed in triple-negative and metaplastic breast carcinomas. Hum Pathol. 2013;44:959-65.

13. Qazi MS, McGregor SM. Combined use of SOX10 and GATA3 in mammary carcinoma. Pathol Res Pract. 2020;216:152801.

14. Jamidi SK, Hu J, Aphivatanasiri C, Tsang JY, Poon IK, Li JJ, et al. SOX10 as a sensitive marker for triple negative breast cancer. Histopathology. 2020. Online ahead of print. 
15. Tozbikian GH, Zynger DL. A combination of GATA3 and SOX10 is useful for the diagnosis of metastatic triple-negative breast cancer. Hum Pathol. 2019;85:221-7.

16. Dwarakanath S, Lee AK, Delellis RA, Silverman ML, Frasca L, Wolfe HJ. S-100 protein positivity in breast carcinomas: a potential pitfall in diagnostic immunohistochemistry. Hum Pathol. 1987;18:1144-8.

17. DeLair DF, Corben AD, Catalano JP, Vallejo CE, Brogi E, Tan LK. Non-mammary metastases to the breast and axilla: a study of 85 cases. Mod Pathol. 2013;26:343-9.

18. Cimino-Mathews A, Harvey S, Argani P. Metastases to the breast. In: Shin S, editor. A comprehensive guide to needle core biopsies of the breast. Switzerland: Springer International Publishing; 2016.

19. Park SY, Kim BH, Kim JH, Lee S, Kang GH. Panels of immunohistochemical markers help determine primary sites of metastatic adenocarcinoma. Arch Pathol Lab Med. 2007;131:1561-7.

20. Dennis JL, Hvidsten TR, Wit EC, Komorowski J, Bell AK, Downie I, et al. Markers of adenocarcinoma characteristic of the site of origin: development of a diagnostic algorithm. Clin Cancer Res. 2005;11:3766-72.

21. Lee AHS, Hodi Z, Soomro I, Sovani V, Abbas A, Rakha E, et al. Histological clues to the diagnosis of metastasis to the breast from extramammary malignancies. Revised version. Histopathology. 2020. Epub ahead of print.

22. Miettinen M, Fernandez M, Franssila K, Gatalica Z, Lasota J, Sarlomo-Rikala M. Microphthalmia transcription factor in the immunohistochemical diagnosis of metastatic melanoma: comparison with four other melanoma markers. Am J Surg Pathol. 2001;25:205-11.

23. Nelson ER, Sharma R, Argani P, Cimino-Mathews A. Utility of Sox10 labeling in metastatic breast carcinomas. Hum Pathol. 2017;67:205-10.

24. Montagnese MD, Roshong-Denk S, Zaher A, Mohamed I, Staren ED. Granular cell tumor of the breast. Am Surg. 2004;70:52-4.

25. Robens J, Goldstein L, Gown AM, Schnitt SJ. Thyroid transcription factor-1 expression in breast carcinomas. Am J Surg Pathol. 2010;34:1881-5.

26. Tornos C, Soslow R, Chen S, Akram M, Hummer AJ, AbuRustum N, et al. Expression of WT1, CA 125, and GCDFP-15 as useful markers in the differential diagnosis of primary ovarian carcinomas versus metastatic breast cancer to the ovary. Am J Surg Pathol. 2005;29:1482-9.

27. Domfeh AB, Carley AL, Striebel JM, Karabakhtsian RG, Florea AV, McManus K, et al. WT1 immunoreactivity in breast carcinoma: selective expression in pure and mixed mucinous subtypes. Mod Pathol. 2008;21:1217-23.

28. Nonaka D, Chiriboga L, Soslow RA. Expression of pax8 as a useful marker in distinguishing ovarian carcinomas from mammary carcinomas. Am J Surg Pathol. 2008;32:1566-71.

29. Kilgore MR, Bosch DE, Adamson KH, Swanson PE, Dintzis SM, Rendi MH. Unexpected PAX8 immunoreactivity in metastatic high-grade breast cancer. Appl Immunohistochem Mol Morphol. 2019;27:637-43.

30. Gurel B, Ali TZ, Montgomery EA, Begum S, Hicks J, Goggins M, et al. NKX3.1 as a marker of prostatic origin in metastatic tumors. Am J Surg Pathol. 2010;34:1097-105.

31. Asch-Kendrick RJ, Samols MA, Lilo MT, Subhawong AP, Sharma R, Illei PB, et al. NKX3.1 is expressed in ER-positive and AR-positive primary breast carcinomas. J Clin Pathol. 2014;67:768-71.

32. Werling RW, Yaziji H, Bacchi CE, Gown AM. CDX2, a highly sensitive and specific marker of adenocarcinomas of intestinal origin: an immunohistochemical survey of 476 primary and metastatic carcinomas. Am J Surg Pathol. 2003;27:303-10.
33. Ritterhouse LL, Wu EY, Kim WG, Dillon DA, Hirsch MS, Sholl $\mathrm{LM}$, et al. Loss of SMAD4 protein expression in gastrointestinal and extra-gastrointestinal carcinomas. Histopathology. 2019;75:546-51.

34. Arpino G, Clark GM, Mohsin S, Bardou VJ, Elledge RM. Adenoid cystic carcinoma of the breast: molecular markers, treatment, and clinical outcome. Cancer. 2002;94:2119-27.

35. Persson M, Andren Y, Mark J, Horlings HM, Persson F, Stenman G. Recurrent fusion of MYB and NFIB transcription factor genes in carcinomas of the breast and head and neck. Proc Natl Acad Sci USA. 2009; 106:18740-4.

36. Kim J, Geyer FC, Martelotto LG, Ng CK, Lim RS, Selenica P, et al. MYBL1 rearrangements and MYB amplification in breast adenoid cystic carcinomas lacking the MYB-NFIB fusion gene. J Pathol. 2018;244:143-50.

37. Poling JS, Yonescu R, Subhawong AP, Sharma R, Argani P, Ning $\mathrm{Y}$, et al. MYB labeling by immunohistochemistry is more sensitive and specific for breast adenoid cystic carcinoma than MYB labeling by FISH. Am J Surg Pathol. 2017;41:973-9.

38. Del Castillo M, Chibon F, Arnould L, Croce S, Ribeiro A, Perot $\mathrm{G}$, et al. Secretory breast carcinoma: a histopathologic and genomic spectrum characterized by a joint specific ETV6-NTRK3 gene fusion. Am J Surg Pathol. 2015;39:1458-67.

39. Tognon C, Knezevich SR, Huntsman D, Roskelley CD, Melnyk N, Mathers JA, et al. Expression of the ETV6-NTRK3 gene fusion as a primary event in human secretory breast carcinoma. Cancer Cell. 2002;2:367-76.

40. Cocco E, Scaltriti M, Drilon A. NTRK fusion-positive cancers and TRK inhibitor therapy. Nat Rev Clin Oncol. 2018;15:731-47.

41. Hechtman JF, Benayed R, Hyman DM, Drilon A, Zehir A, Frosina $\mathrm{D}$, et al. Pan-Trk immunohistochemistry is an efficient and reliable screen for the detection of NTRK fusions. Am J Surg Pathol. 2017;41:1547-51.

42. Harrison BT, Fowler E, Krings G, Chen YY, Bean GR, VincentSalomon A, et al. Pan-TRK immunohistochemistry: a useful diagnostic adjunct for secretory carcinoma of the breast. Am J Surg Pathol. 2019;43:1693-700.

43. Chiang S, Weigelt B, Wen HC, Pareja F, Raghavendra A, Martelotto LG, et al. IDH2 mutations define a unique subtype of breast cancer with altered nuclear polarity. Cancer Res. 2016;76: 7118-29.

44. Lozada JR, Basili T, Pareja F, Alemar B, Paula ADC, GularteMerida R, et al. Solid papillary breast carcinomas resembling the tall cell variant of papillary thyroid neoplasms (solid papillary carcinomas with reverse polarity) harbour recurrent mutations affecting IDH2 and PIK3CA: a validation cohort. Histopathology. 2018;73:339-44.

45. Yan H, Parsons DW, Jin G, McLendon R, Rasheed BA, Yuan W, et al. IDH1 and IDH2 mutations in gliomas. N Engl J Med. 2009;360:765-73.

46. Pareja F, da Silva EM, Frosina D, Geyer FC, Lozada JR, Basili T, et al. Immunohistochemical analysis of IDH2 R172 hotspot mutations in breast papillary neoplasms: applications in the diagnosis of tall cell carcinoma with reverse polarity. Mod Pathol. 2020;33:1056-64.

47. Alsadoun N, MacGrogan G, Truntzer C, Lacroix-Triki M, Bedgedjian I, Koeb MH, et al. Solid papillary carcinoma with reverse polarity of the breast harbors specific morphologic, immunohistochemical and molecular profile in comparison with other benign or malignant papillary lesions of the breast: a comparative study of 9 additional cases. Mod Pathol. 2018;31:1367-80.

48. Cottrell TR, Taube JM PD-L1 and emerging biomarkers in immune checkpoint blockade therapy. Cancer J. 2018;24:41-6.

49. Walk EE, Yohe SL, Beckman A, Schade A, Zutter MM, Pfeifer J, et al. The cancer immunotherapy biomarker testing landscape. Arch Pathol Lab Med. 2020;144:706-24. 
50. Taube JM, Galon J, Sholl LM, Rodig SJ, Cottrell TR, Giraldo NA, et al. Implications of the tumor immune microenvironment for staging and therapeutics. Mod Pathol. 2018;31:214-34.

51. List of cleared or approved companion diagnostic devices (in vitro and imaging tools). U.S. Food and Drug Administration (FDA). 2020. https://www.fda.gov/medical-devices/vitro-diagnostics/listcleared-or-approved-companion-diagnostic-devices-vitro-and-ima ging-tools.

52. Topalian SL, Taube JM, Pardoll DM. Neoadjuvant checkpoint blockade for cancer immunotherapy. Science. 2020;367:eaax0182.

53. Lu S, Stein JE, Rimm DL, Wang DW, Bell JM, Johnson DB, et al. Comparison of biomarker modalities for predicting response to PD-1/PD-L1 checkpoint blockade: a systematic review and metaanalysis. JAMA Oncol. 2019;5:1195-204.

54. Narayan P, Wahby S, Gao JJ, Amiri-Kordestani L, Ibrahim A, Bloomquist E, et al. FDA approval summary: Atezolizumab plus paclitaxel protein-bound for the treatment of patients with advanced or metastatic TNBC whose tumors express PD-L1. Clin Cancer Res. 2020;26:2284-9.

55. Malhotra MK, Emens LA. The evolving management of metastatic triple negative breast cancer. Semin Oncol. 2020;47:229-37.

56. Schmid P, Adams S, Rugo HS, Schneeweiss A, Barrios CH, Iwata $\mathrm{H}$, et al. Atezolizumab and Nab-Paclitaxel in advanced triplenegative breast cancer. N Engl J Med. 2018;379:2108-21.

57. Cortes J, Cescon DW, Rugo HS, Nowecki Z, Im S-A, Yusof MM, et al. KEYNOTE-355: randomized, double-blind, phase III study of pembrolizumab + chemotherapy versus placebo + chemotherapy for previously untreated locally recurrent inoperable or metastatic triple-negative breast cancer. J Clin Oncol. 2020;38:1000.

58. Schmid P, Cortes J, Pusztai L, McArthur H, Kümmel S, Bergh J, et al. Pembrolizumab for early triple-negative breast cancer. $\mathrm{N}$ Eng1 J Med. 2020;382:810-21.

59. Scheerens H, Malong A, Bassett K, Boyd Z, Gupta V, Harris J, et al. Current status of companion and complementary diagnostics: strategic considerations for development and launch. Clin Transl Sci. 2017;10:84-92.

60. Ventana PD-L1 (SP142 Assay) Interpretation guide for triplenegative breast carcinoma (TNBC). Ventana Medical Systems, Inc. and Roche Diagnostics International, Inc. 2019. https://dia gnostics.roche.com/us/en/landing-pages/guide-tnbc-therapydecisions-with-confidence.html.

61. Cimino-Mathews A, Thompson E, Taube JM, Ye X, Lu Y, Meeker A, et al. PD-L1 (B7-H1) expression and the immune tumor microenvironment in primary and metastatic breast carcinomas. Hum Pathol. 2016;47:52-63.

62. Cimino-Mathews A, Ye X, Meeker A, Argani P, Emens LA. Metastatic triple-negative breast cancers at first relapse have fewer tumor-infiltrating lymphocytes than their matched primary breast tumors: a pilot study. Hum Pathol. 2013;44: 2055-63.
63. Szekely B, Bossuyt V, Li X, Wali VB, Patwardhan GA, Frederick $\mathrm{C}$, et al. Immunological differences between primary and metastatic breast cancer. Ann Oncol. 2018;29:2232-9.

64. Li Y, Chang CW, Tran D, Denker M, Hegde P, Molinero L. Abstract PD6-01: prevalence of PDL1 and tumor infiltrating lymphocytes (TILs) in primary and metastatic TNBC. Cancer Res. 2018;78:PD6-01.

65. Rimm DL, Han G, Taube JM, Yi ES, Bridge JA, Flieder DB, et al. Reanalysis of the NCCN PD-L1 companion diagnostic assay study for lung cancer in the context of PD-L1 expression findings in triple-negative breast cancer. Breast Cancer Res. 2019;21:72.

66. Rimm DL, Han G, Taube JM, Yi ES, Bridge JA, Flieder DB, et al. A prospective, multi-institutional, pathologist-based assessment of 4 immunohistochemistry assays for PD-L1 expression in non-small cell lung cancer. JAMA Oncol. 2017;3:1051-8.

67. Reisenbichler ES, Han G, Bellizzi A, Bossuyt V, Brock J, Cole K, et al. Prospective multi-institutional evaluation of pathologist assessment of PD-L1 assays for patient selection in triple negative breast cancer. Mod Pathol. 2020;33:1746-52.

68. Vennapusa B, Baker B, Kowanetz M, Boone J, Menzl I, Bruey J$\mathrm{M}$, et al. Development of a PD-L1 complementary diagnostic immunohistochemistry assay (SP142) for Atezolizumab. Appl Immunohistochem Mol Morphol. 2019;27:92-100.

69. Martinez-Morilla S, McGuire J, Gaule P, Moore L, Acs B, Cougot D, et al. Quantitative assessment of PD-L1 as an analyte in immunohistochemistry diagnostic assays using a standardized cell line tissue microarray. Lab Invest. 2020;100:4-15.

70. Gaule P, Smithy JW, Toki M, Rehman J, Patell-Socha F, Cougot $\mathrm{D}$, et al. A quantitative comparison of antibodies to programmed cell death 1 ligand 1. JAMA Oncol. 2017;3:256-9.

71. Lee SE, Park HY, Lim SD, Han HS, Yoo YB, Kim WS. Concordance of programmed death-ligand 1 expression between SP142 and 22C3/SP263 assays in triple-negative breast cancer. J Breast Cancer. 2020;23:303-13.

72. Torlakovic E, Lim HJ, Adam J, Barnes P, Bigras G, Chan AWH, et al. "Interchangeability" of PD-L1 immunohistochemistry assays: a meta-analysis of diagnostic accuracy. Mod Pathol. 2020;33:4-17.

73. O'Malley DP, Yang Y, Boisot S, Sudarsanam S, Wang JF, Chizhevsky V, et al. Immunohistochemical detection of PD-L1 among diverse human neoplasms in a reference laboratory: observations based upon 62,896 cases. Mod Pathol. 2019;32:929-42.

74. Sun WY, Lee YK, Koo JS. Expression of PD-L1 in triple-negative breast cancer based on different immunohistochemical antibodies. J Transl Med. 2016;14:173.

75. Rugo HS, Loi S, Adams S, Schmid P, Schneeweiss A, Barrios $\mathrm{CH}$, et al. LBA20 - performance of PD-L1 immunohistochemistry (IHC) assays in unresectable locally advanced or metastatic triplenegative breast cancer (mTNBC): post-hoc analysis of IMpassion130. Ann Oncol. 2019;30:v858-9. 